\title{
COMMENTARY ARTICLE
}

\section{Regarding the Relationships of Surgeons, Colleagues, and Patients}

\author{
Author \\ Lawrence Hergott \\ Email: lawrence.hergott@ucdenver.edu
}

\section{$\underline{\text { Prologue }}$}

Thank you, friends of Surgery, and the European Society of Medicine, for asking me to write in the Advances of Surgery.

I am a cardiologist in the United States, so you might wonder, as do I, why I have been invited to write an essay in Advances in Surgery. I am a medical writer, but mostly of essays and poems. I do have a recent book published, Departure From the Darkness and Cold: the Hope of Renewal for the Soul of Medicine in Patient Care - 50 essays and poems describing interactions between patients and clinicians manifesting the soul of medicine - some of which are in this manuscript.

I believe I was asked to write the essay because Dr. L. Smith, of the European Society of Medicine, was interested in one of my poems, On Duty In the Surgery Waiting Room. I am honored to write the dissertation, which embodies many new thoughts, and some relevant, already published essays and poems. Expressions of my interactions with surgical physicians are dominantly meant to hopefully recall similar events in your medical history. If you just like to read, simply enjoy what is written.

An example of what is written begins when I asked an anesthesiologist some years ago which surgeon I should ask to operate on my wife for a difficult procedure, the anesthesiologist responded by saying, "I will give you three names, each of which is an excellent surgeon." He then gave me three names. However, all three were the same name. I immediately understood, and I asked the surgeon to do the operation, and he courteously agreed. The procedure was done.

The final paragraph in this entire commentary will explain what happened that day - the relevance of the poem that Dr. Smith found appealing, what happened to me, how I felt about the surgeon, and why the name of the essay is so. 


\section{$\underline{\text { Beginning }}$}

From the first day in medical school to the day we walk out of our office or hospital we are deepening - from the enlightening data we learn each day, the awareness of personality in both self and others, the unimaginable wonders of medicine, and the scant but brutally horrific days we may never forget. This dissertation will cover a large exposition of how and why those days exist. We will begin with a poem that begins in sparce awareness and offers a thickened medical life.

The Marvel of the Uncarved Block

For a First Year Medical Student

A journey of a thousand miles starts from beneath one's feet.

-- Tao Te Ching LXIV,153
The things of a man for which we visit him were done in the dark and the cold.

-- Ralph Waldo Emerson

You might wonder now whether you chose the better path.

There were ways you could have helped others

on benevolent and spirited trails.

But there is only one way to do what a doctor does,

and be what a doctor is -

which is the reason you gave voice to the terminal, 'Yes,'

and entered the forest.

Now you have become

what the tao declares,

the 'Uncarved Block' -

a state of pure potential,

the primordial condition of the mind before the arising experience.

Your work carving the block

will be brutal.

A senior student said to a beginner,

'If you are not in a total state of shock

your first few months of medical school

you don't understand what is going on.'

Your work carving the block

will also be long -

moving slowly, diligently, laboriously -

toward the self you want to be,

perhaps at times feeling you cannot.

You can. 
I know.

I have -

and not easily.

\section{Carve.}

It is your carving that endures.

It is your enduring that transforms -

from uncarved block to sage, to sensing the presence of those, grateful, who come to visit you.

There are many times, over many years, when apprehensive medical trainees - medical students, interns, residents, and fellows - could benefit from concurring with the last stanza of the poem.

\section{The Quandary}

The practice of medicine is an art, not a trade; a calling, not a business;

a calling in which your heart will be exercised equally with your head.

-- Sir William Osler

The essays and poems will be principally about general surgeons, but also of various types of other surgeons and doctors who worked with them, and patients they cared for. As our base, we will be understood that there have been major problems in patient care for the last twenty years in both Europe and the United States (e.g., see 2019 online survey of nearly 20,000 doctors: Medscope Global Physicians' Burnout and Lifestyle ), and the ongoing Covid-19 horror.

The international 20-year epidemic of caring for patients and ourselves has failed mostly due to a shift from clinical management to that of nonclinical administrators: business oriented healthcare organizations, insurance companies, hospital executives, excessive government regulation, etc. Parties developing our reconstruction together could benefit from reflecting on the fact that Daedalus did not simply tell Icarus to keep from flying too close to the sun. He ordered Icarus to fly the middle course and avoid not only the heat of the sun but the spray of the sea, which could bring him down - and which did in medical care. Achieving our goal after Covid-19 will require an even more broadly perspective than before.

Working together in cooperation rather than seclusion in administration especially, all of us learning from our mistakes, and dedicated to the benefit of others more than ourselves, we can create a lifegiving and honorable system. It is in hope that such an alliance will pronounce as its 
foundation a quote from the Chinese sage, Chuang Tzu: "When the heart is right, For and Against are forgotten."

As Dr. Donald M. Berwick, of the Institute for Healthcare Improvement in the U.S., stated for all: "It has long seemed a paradox to me that such depletion of joy in work can pervade as noble and meaningful an enterprise as health care.... We have chosen a calling that invites people who are worried and suffering to share their stories and allow us to help. If any work ought to give spiritual satisfaction to the workers, this is it. 'Joy,' not 'burnout,' ought to rule the day."

Though declared over more than a century, Sir William Osler's proclamation regarding the practice of medicine persists and must. If after Covid-19 clinicians focus only on the biomedical, not the personal, patients and clinicians will never again feel the essence, wellness, and soulfulness of medicine.

What may be needed to return to such could be understood by what Jean Cocteau declared about creativity: "The muses don't invite you in. They open the door and point to the tightrope."

The poem, A Separate Sacrifice, describes what effort it has to completely care for our patients:

\section{A Separate Sacrifice}

The dimly lit hospital corridor

looks at dusk as it did at dawn.

The patient list in hand, though,

appears much different in the evening light:

names, numbers, tasks-

added, underlined,

crossed off, moved-

cryptic symbols of a day's noble work done

and not yet done.

Moving to the next bedside,

weary, committed, sacrificial mantle felt, I glance toward a westerly window and am uncaring

to be unmoved

by the known-rapturous palette of an evening's fleeting majesty-

my soul obscured

until long after duty and privilege are discharged, the list is satisfied,

and its servant late away. 
My beloved's greeting kindles

any time of day

or night.

Food can be rewarmed.

But a day's excited story from a child

now asleep,

told by another,

is absent what could have been eternal between us-

a separate sacrifice

that saddens the most noble heart. ${ }^{1}$

Being an elderly cardiologist, I have worked with surgeons habitually, and for decades. Because surgeons do their work so well, they do not often halt to perceive their prominence, or often mention a clinical response. The outcomes are from work - hour after hour, day after day, week after week. The stories told in these essays and poems offer doctors to occasionally pause, and perhaps feel the benefits by doing so - going beyond the biomedical, and reflecting on the medical life in its whole, including its personal life. A short essay describes a cardiothoracic surgeon who paused and considered his medical-personal life. The essay's title is, The Desktop Photo:

"The small photograph that sits alone on the office desk of a surgical colleague tells a lifesaving story. Indicative of its importance to him, the photo has rested on his desk since the day he first occupied the office nearly a decade ago. Like the other artifacts he has placed around the room, though, each chosen for its meaning or its beauty, over time the photo has assumed a background role. He hardly notices the objects as he does his work there. Attention is directed instead toward papers that cross his desk, images that come and go on his computer screen, work on the phone, staff and colleagues entering and leaving, and ever-present thoughts in between about clinical or administrative issues. But the manner in which he attends to these tasks, the way he treats his patients, even how he performs their operations, has much to do with the stories the artifacts tell. They are reflective of the formative and sustaining things he has experienced that make him the doctor and person he is. On a recent occasion he did take the picture off his desk to look at it, and what it conjured up brought him to tears. For the life saved in the story the picture tells is not the life of a patient, but of his own family.

The picture shows two little girls in their pajamas sitting on a bed holding a telephone. They are saying good night to him, their father, still at work. This they commonly did since he was a member of a group that scheduled operations well into the evening. Present in the scene, though not in the picture, is the girls' mother, who took the photo for reasons and feelings of her own. The scene speaks of innocence, separation, unfortunate and recurring compromise - and hints at possible regrettable future realities.

Inscribed on the picture are the words 'Thank You Daddy' — an obscure inclusion, until he explains 'Thank You Daddy' was written by the girls later, the picture then framed and presented to their father in thanks for his leaving that practice for one that allowed him to be home most evenings. The completed scene speaks of caring, responsiveness, optimism and wholeness.

The photo serves as an emotive reminder for him of what was and might have been - and of what is, the family together and well, and he perhaps the most thankful of all for having made the 
decision he did." ${ }^{2}$

The cardiothoracic surgeon recognized that there can be "Shadows cloaked in light," as Baltasar Gracian warned us about in the 17th century - and recognized as well the passage of the Tao Te Ching that speaks of a water-bearing vessel that tips over when filled to the brim but remains upright when filled to a lower level.

Five years after deliberating from his medical-personal life and leaving to a different, more gentle group, United States Medicare - which cares for all patients older than 65 years-old in the U.S. - listed his group of cardiac surgeons and cardiologists in the top 5\% of excellent care in the nation. His family is also well.

\section{Personal Memories of Surgeons}

I have deeply thought recently about stories of individual surgeons whom I worked with. I recall only three that came to mind - all of which are from my early years as a physician. The first story is that of my father developing a gallstone at age sixty-two. Since I was in the fourth year of medical school, I got a well-known surgeon at my university to take care of my father. My father was placed in the university hospital and quickly an electrocardiogram showed that he had two unknown previous heart attacks. A prominent and caring cardiologist came to see my father, and after assessing his cardiac disease, told my father he should not undergo surgery, and that he could die if he did.

My father agreed and was getting ready to go back home when an obvious arrogant chief resident in surgery arrived in his room and told my father that the procedure would not cause him any trauma, nor would he die from it. My father agreed to proceed with the surgery. As a fourthyear medical student I did not know what should be done.

The next day, after a very long operation, my father died shortly after returning to his room.

I never heard from the chief resident again.

We meet few villains in medicine, but the second experience that came to my mind occurred when I was in my last cardiology fellow year. While working in a small hospital's emergency room one Sunday afternoon, a 16-year-old girl came in with pain in her right inguinal area, with more pain in tender pressure, and elevated white blood cells. The young girl clearly had appendicitis, so I called the surgeon on duty, whose house and car I could see across a corn field. After 45 minutes I called him on the phone again, and said the child was very uncomfortable. After another 45 minutes I called the doctor and told him the pain had abated, and thus the appendix had ruptured.

The doctor then came quickly to the hospital and told me he wanted to have dinner with his family before he came to operate on the child. Knowing more than I did as a medical student, I called the hospital's director the next day and told him what had happened. The doctor was put on probation by the hospital's manager.

The third experience I recalled was the opposite of the others, a truly touching event of a fiveyear-old child and a surgeon. The pediatrician caring for our children had detected a swollen and 
mildly painful inguinal nodule in our son and told us he would need an operation. He recommended a specific surgeon to do the procedure.

I recall that my son, Zachary, did not have a visit in the surgeon's office prior to the day of the procedure. Rather, the surgeon met Zachary in a waiting room prior to the procedure, with my wife and I as well. The surgeon was very gentle with Zachary as he told us all why the procedure needs to be done, how it is done, and that after the procedure there would be an hour after Zachary could go home to heal.

What makes me remember now is what happened when time came for Zachary to leave us and go to the operative room. I expected a nurse to take Zachary to the operative room, where he would meet the surgeon again - in a scary room, with a hat, mask, and surgical gown on, ready to operate.

However, what makes me not only remember the day, but tear up as I write this - just like I did when Zachary walked to the operation room that day, decades ago. Why? There was no nurse present. There was no other person who would be present to take Zachary to the surgical room. Rather, the surgeon stood up (two meters in height), took Zachary's hand gently, and talked softly to him as they he walked to the surgical room.

I digress to share that our family has somewhat of another story, when our daughter was in an ongoing 36-hour labor - our knowing again a loved one was in peril, in the hands of another physician, with nothing we could do to help. A poem did arise from those two stories, Sala de Esperanza:

The sign on the hospital wall

identifying the space

begins with a Spanish phrase-

sala de espera,

waiting room.

A more symbolic phrase

may have deeper meaning

for those awaiting news of loved ones there-

sala de esperanza,

room of hope.

Those waiting

can do little but hope-

yet hope is everything to them

in that often-desperate time

of craving favorable answers

to tormenting questions.

Is he alive?

Are baby and mother all right?

Did you get it all?

Will she be able to walk, 
to talk,

to come home?

The value of those in the sala de esperanza

hoping

is not to affect

the answers to such questions.

They cannot.

The value of hoping

is the clarity

of the love of those who wait

for whom they wait. ${ }^{3}$

I mention the first two events because I never had a bad experience with a surgeon since. In over 40 years in training, being a cardiologist, and working with surgeons often in those years, the two 'doctors' mentioned were the worst surgeons I came across.

When I was an early cardiologist a senior surgeon said to me, "There are 'doctors' and there are 'physicians."' He said that doctors know medicine, and how to treat patients. Physicians are that as well, he said, but are more aware and interacted with patients, other doctors, nurses, etc., and "are better doctors, being broader all around."

I know what he meant, but it is not true. I would rather have a quiet, or even surly, excellent doctor treating or operating on me than an affable one who is not as good in the surgery room. One well known surgeon in my city is typically so nasty during a procedure that the nurses assisting him get more money to work with him. However, he is one of only four surgeons noted in the highest in the state and said so by the rest of the other surgeons.

The words 'doctor' and 'physician' are the same.

\section{$\underline{\text { A Continued Sorrow }}$}

Though I have rarely heard of poor or appalling medical care for decades, there are times when physicians' cases go wrong. A poor patient outcome rarely signifies negligence or misjudgment on the part of the physician. No matter the specifics of the damage done, however, thoughtful physicians take any harm to a patient both seriously and personally. The forebear of angioplasty, the late German Andreas Gruentzig, told us that if we were going to do angioplasty we should, "expect complications." What he said can be expanded to the practice of medicine in general: If you are going to be a physician, deciding hourly about things that affect the health and lives of patients and their loved ones, expect some bad outcomes. They will occur, no matter how careful or how good you are.

Though rare, mistakes can cause damage, or even death, to a patient. I know how my self, as written in the essay, A Single Cloud Eclipses the Sun. 
"'The sound of a coffin hitting earth is a sound utterly serious." -- Antonio Machado, The Burial of a Friend

I think about him several times a year even now, more than 30 years later. When I do it is with uncomfortable clarity and a surge of briefly incapacitating sadness and guilt. He had come to the office at the age of 62, troubled by chest tightness and shortness of breath with exertion. Intelligent and gentle, he was the kind of person you would look forward to seeing over the years. His physical examination revealed a heart murmur suggestive of severe aortic valve stenosis (narrowing), which implied a potential reduction of blood flow to the entire body with physical effort. My training, completed just months before, had taught me that it was too dangerous to exercise such patients to assess whether or not their symptoms were cardiac in origin. Rather, cardiac catheterization to determine the severity of the stenosis and coronary angiography in preparation for aortic valve replacement were appropriate. In the practice world, though, many physicians exercised such patients routinely, and after conferring with colleagues who were my senior I put my patient on the treadmill.

Not long into the test, he suddenly said he felt very bad. He lost the rhythm of his gait and was unable to keep up with the treadmill, which we quickly stopped. Woozy and barely able to step off the belt, he turned his head up and slumped to the floor. The electrocardiogram showed a regular heart rhythm and was without evidence of a heart attack. His blood pressure was unobtainable. The pathophysiology of what had happened was obvious: exercise-induced dilation of his arteries and thus marked reduction of blood pressure in the setting of what truly was severe aortic stenosis. Also clear was the necessity of rapid resuscitation if we were to save his life. But the resuscitation was unsuccessful, and he died there on the floor without regaining consciousness. Stunned, the nurses and I knelt silent and immobile next to him. But the horror was not over. I still had to phone his wife, who waited at home. Making the call was in its way as hard as witnessing his death. She too seemed a lovely person and though dazed was remarkably understanding. She related that just before he left the house, he had told her, "If they put me on the treadmill I don't think I will make it." He had not expressed that to me, deferring to the judgment of his cardiologist.

I have wondered over the years how long he might have lived had we been able to replace his aortic valve successfully. Would he have been alive when I thought about him in 1990? In 2000? In 2010? Is she alive? Did she live the rest of her life alone? There are two ways the death of a loved one affects people: the dying process is one, the loved one's absence the other-and often worse. She suffered the shock of the first and the loneliness of the latter. So much in life depends on who comes beside. Their journey together ended with his coming to see me. I expressed my sorrow to her then and would again if given the chance. It is painful to write about and utterly serious still.

On occasion I envision myself kneeling at my aortic stenosis patient's side after the unsuccessful resuscitation and hearing again the sound of his wife's voice on the phone. Doing so brings a sudden inner darkness, making real in a physical way something Balthasar Gracian described in the 17th century, a single cloud that eclipses the sun.'

It has only been a few years that I have allowed myself to think something else on that day.

'But, inspired by the soul of medicine, dedicated to medical practice, and motivated by the awareness of how much good there is yet to be done, I am heartened as my workday continues and I help people, as 
others help me - and feel once more the warmth of the sun and the mostly brilliant blue sky that medical practice is by its nature.' 4

\section{$\underline{\text { Regarding a Letter to a Dying Friend }}$}

A powerful and helpful poem for both doctors and friends is that of a different kind of death, one that has not occurred, but with both of the people knowing it will. The poem, Regarding a Letter to a Dying Friend, has been helpful in many ways for many people, including in medicine, when the person has not yet parted.

Through long hours and too many deaths,

this I have learned:

every word counts now.

Your friend spends his days

consumed by the news.

He needs you.

Choose your words thoughtfully, and not about you.

Write nothing that derails or otherwise impairs

the one with little time left.

Write something soon that kindles your bond.

Thank him for enriching your life, and for his many affections compelling you to write to him.

Tell him of your heavy sadness to learn that the tumor had spread, that the agonizing treatments had failed.

Manifest respect, and concern, never pity.

Tell him how moved you are by his courage.

Emphasize the obvious in himno surprise-

an unremitting sense of

strength, and grace.

Sing his praises for these. 
Send gifts.

His life is not over.

Send yourself.

Give the gift of your presence on his end journey, declaring that, far away, you cannot walk with him but you can walk beside him in spirit.

Give him the gift of knowing he matters now and always will, that with your own immense loss memories of him will live in you forever.

When that time comes to say goodbye, give him the greatest gift, and tell him you love him. ${ }^{5}$

\section{Epilogue}

I mentioned early in this dissertation that it was written because Dr. L. Smith was interested in a poem I wrote. I will place the poem and then explain why Dr. Smith and I both find it interesting, though I suspect for different reasons. The poem is:

\section{On Duty in the Surgery Waiting Room}

Walking in, I recognized the wood floor and furniture in the room.

Having worked in that hospital for twenty years

I had been in the room many times attending to patients' loved ones.

This time it was I who waited for the doctor, and the news.

My beloved was having a medium-risk procedure.

Though not believing the legend that medical families have more complications than others, I still worried about the worst, and took a seat in the corner.

A family entered, 
led by an elderly, stately man -

Irish-looking, I thought.

He was accompanied by what appeared to be

two middle-aged daughters

and a teenage granddaughter

with numerous pierced jewelry on her face and ears.

Of the four

he seemed the most concerned.

I noticed his wedding ring.

If I were on duty, I thought,

I would approach him.

"Who is it that you're waiting for?" I would ask.

"Tell me about her."

Thankful not to be on duty,

I turned away.

His daughters frequently spoke to him

as they waited.

The granddaughter told of her new boyfriend,

with whom she was quite taken.

"Well, he seems like a fine fellow,"

the grandfather said.

He later changed seats and moved toward a daughter

who was sitting near me.

After a time he turned to me

and said in an Irish brogue,

"Who is it that you're waiting for?"

"Tell me about her."

What the elderly Irish man said startled me and warmed my heart. I wanted to softly tell him about my wife, and not say I was a doctor. I did not feel like a doctor. Before I could say anything to him our surgeon walked into the room. All I could do was thank the man and stand to walk toward the surgeon. I had seen the Irish man's shining wedding ring, and I hope his wife was as well as mine after her surgery.

The doctor was not smiling, nor speaking in a jovial way. His speaking was in a warm way, though, and he said my wife was fine, the procedure went very well, and she would go home in a few days, as usual after that procedure.

I could tell he was pleased about the procedure, but not arrogant. He asked if I had any questions, and if any came up, I should call him.

Then he left, to the next place where he would be of help, imbedded deeply within him the days from his uncarved block to the bedside of a dying patient - and manifesting poet Robert Frost's declaration, "Such as we were, we give ourselves outright."

And so did I go, to my mended beloved, deeply grateful for the surgeon and many others. 
I thank Dr. L. Smith, the European Society of Medicine, and European surgeons for the opportunity to write for Advances of Surgery.

LJH, MD

\section{$\underline{\text { References }}$}

1. Hergott L. Desktop Photos. Canadian Medical Association Journal. 2006;175:781.

2. Hergott L. A Separate Sacrifice. Annals of Internal Medicine. 2007;147(12):896.

3. Hergott L. Sala de Esperanza. Annals of Internal Medicine. 2012;156:66.

4. Hergott L. Playing the Moonlight Sonata from Memory: Celebrating the Wonders of Our Difficult Life. JAMA. 2013;310(2):147-148.

5. Hergott L. Regarding a Letter to a Dying Friend. Annals of Internal Medicine. 2019;170(4):274.

6. Hergott L. On Duty in the Surgery Waiting Room. Annals of internal Medicine. 2020;172(3):220. 